\title{
Teses e dissertações do Programa de Estudos Pós-Graduados em Teologia da PUC/SP, defendidas no $1^{0}$ semestre de 2015
}





\title{
A teologia da cruz na cristologia latino-americana
}

\author{
Leandro Carlos Pereira
}

Titulação: Mestre em Teologia

Orientador: Dr. Antônio Manzatto

Data da Defesa: 10/02/2015

Resumo: A teologia da cruz sempre teve profunda relação entre o povo latino- americano e Jesus Cristo, que sofreu e morreu na cruz, apontando os elementos de uma cristologia libertadora da cruz. Pois os sofrimentos do Cristo crucificado, hoje, estão presentes nos nossos pobres, nos operários mal assalariados, nas crianças subnutridas, desamparadas e exploradas sexualmente, nos jovens desnorteados e explorados pelo tráfico de drogas e excluídos do campo da educação, do trabalho e das oportunidades, e também dos nossos idosos que são descartados pela cultura do utilitário que os identifica com "sucata" a ser descartada. Nosso estudo procura identificar a compreensão da cruz na cristologia latino-americana a partir dos povos crucificados da história, pois inútil e infrutuosa seria a reflexão sobre a cruz do Cristo histórico se não olhássemos e apontássemos para estes povos crucificados que prosseguem sua caminhada rumo ao calvário, em nossa querida e amada América Latina marcada pela exploração dos mais pobres. A cruz é símbolo que conduz para fora da Igreja e do anelo religioso para dentro da comunhão com os crucificados da história. Em sentido reverso, ela é símbolo que chama os oprimidos e os ímpios para a Igreja, e por meio dela, para a comunhão com o Deus crucificado que se fez o Deus conosco. Tornar a cruz presente em nossa cultura significa não se acomodar, nesta sociedade, aos seus ídolos e tabus, temores e fetiches, mas em nome daquele que no passado foi sacrificado pela religião, sociedade e Estado, solidarizar-se com as vítimas atuais da religião, sociedade e Estado, fazendo-se, tal como Jesus crucificado, irmão e libertador delas.

Palavras-chave: Cruz; Crucificados; Pobres; Excluídos; Marginalizados; Redenção; Solidariedade; Esperança. 


\title{
Missão e igreja local: um estudo do Vodu haitiano no contexto do pluralismo religioso
}

\author{
Jean Anel Joseph
}

Titulação: Mestre em Teologia

Orientador: Dr. Kuniharu Iwashita

Data da defesa: 25/02/2015

Resumo: A missão recebida de Jesus Cristo (cf. Mt 29, 19-20) é assumida pela Igreja Universal e é efetiva na atividade de cada Igreja local. No entanto, entendemos que uma Igreja se torna particular quando chega à maturidade de assumir elementos culturais locais e se empenha na inculturação do Evangelho nesta determinada realidade. Com efeito, a missão de fazer conhecer Jesus Cristo até os confins da terra enfrentou desafios de línguas, mentalidades e culturas. É a partir do processo da inculturação que podemos verdadeiramente propor um Jesus Cristo encarnado com a missão de libertar e salvar o gênero humano. Mas, nem sempre, o processo da Evangelização está livre de concepções culturais dos seus evangelizadores e, na maioria das vezes, as culturas dos povos nativos foram combatidas ou ignoradas. Esta pesquisa estuda a realidade haitiana no choque cultural entre o processo da evangelização cristã e o Vodu. Tentamos contextualizar tanto o discurso da Igreja local como os seus próprios escritos no cenário internacional e também o vasto pensamento teológico daquela época. Expomos também o trabalho dos negros pelo reconhecimento da cultura negra, defendendo-a contra todo o preconceito de cultura atrasada, de juiz de valor de fetichismo, bruxaria e tantos outros títulos que foram empenhados para combater a cultura negra em que o Vodu é uma forma de expressão. Depois de analisar o modo com que a Igreja local desempenhava a sua atividade missionária em relação ao Vodu e à luz do Vaticano II, procuramos apontar possíveis saídas de posicionamentos que podem levar a uma convivência entre as 
duas religiões que atualmente se encontram, perante a lei, sob o mesmo grau de importância, mas teológica e soteriologicamente, procuramos afirmar a superioridade de Jesus Cristo. Nós não ignoramos a presença das outras religiões, contudo colocamos nosso foco em estudar e apresentar elementos pastorais para uma possível superação dos desafios atuais, neste novo contexto plural que pinta a realidade haitiana, com o reconhecimento jurídico do Vodu como religião e a chegada de novas confissões religiosas com a missão da ONU, presente no Haiti desde 2004. Enfim, salientamos a hipótese de que a volta às práticas pré-conciliares só podem prejudicar a atividade da Igreja local se ela quiser estar em sintonia com a missão universal da Igreja e, principalmente, se ela pretende responder ao apelo do Magistério Continental e mais especificamente a Aparecida, que clama por uma conversão pastoral como resposta adaptada aos sinais dos tempos atuais.

Palavras-chave: Missão; Vodu haitiano; Inculturação; Igreja local. 


\section{A favorita do harém: exegese do Salmo 45}

Fabiana de Sousa

Titulação: Mestre em Teologia

Orientador: Dr. Matthias Grenzer

Data da defesa: 12/03/2015

Resumo: O objetivo da presente Dissertação de Mestrado é analisar, exegeticamente, o poema presente no Salmo 45, sobretudo sua beleza literária, seu contexto histórico e suas dimensões teológicas. Os capítulos seguem a subdivisão do poema em estrofes. Analisando-se dessa forma trecho por trecho, primeiramente dá-se atenção ao texto hebraico, sendo que este, a partir dos estudos filológicos, é traduzido para o português da forma mais literal possível. Em seguida, os estudos se dedicam à observação dos elementos estilísticos, como, por exemplo, os diversos paralelismos ou a formação das estrofes, sendo que estas últimas constituem pequenas unidades literárias. Por fim, a pesquisa aqui apresentada se concentra nos diversos elementos do provável contexto histórico e nas dimensões teológicas veiculadas pelo Salmo 45. De um modo especial, o estudo se preocupa em acolher os princípios da exegese canônica, através da observância dos paralelismos presentes na Bíblia Hebraica, partindo-se da ideia de que os textos bíblicos se explicam mutuamente.

Palavras-chave: Salmo 45; Realeza; Esposa do rei; Harém. 


\section{Justiça de Deus e justificação: estudo exegético de Rm 1,16-17}

Roberto Almeida da Paz

Titulação: Mestre em Teologia

Orientador: Dr. Boris Agustín Nef Ulloa

Data da defesa: 16/03/2015

Resumo: Este trabalho estuda os aspectos hermenêuticos da justiça e da justificação na Carta aos Romanos. Seu escopo é trazer à superfície o conteúdo substancial da justificação pela fé na teologia paulina, enfatizada na perícope de Rm 1,16-17. Examina, em seguida, os desdobramentos inerentes ao arcabouço da justificação, como princípio de salvação do ser humano (Judeu e Grego), pela gratuidade e iniciativa divina. Objetiva-se compreender a noção de justificação, visando a detectar sua estrutura conceitual e os conceitos teológicos com os quais ela se relaciona, tais como justiça, evangelho, fé, reconciliação, salvação etc. Além disso, o caminho exegético aqui seguido apresentará uma radiografia da compreensão de Paulo, segundo a qual o ser humano é justificado pela fé em Cristo e pelo Espírito. A conclusão propõe algumas reflexões sobre a atualidade do tema, em detrimento de uma compreensão açodada, segundo a qual a justificação é essencialmente fruto da teologia protestante.

Palavras-chave: Evangelho; Fé; Espírito Santo; Dom; Esperança; Justiça de Deus; Justificação; Salvação; Jesus Cristo. 


\section{A conclusão da obra lucana: um estudo exegético-teológico de At 28,16-28}

Guilherme Pereira Anselmo Júnior

Titulação: Mestre em Teologia

Orientador: Dr. Boris Agustín Nef Ulloa

Data da defesa: 18/03/2015

Resumo: O conjunto dos textos do livro do Evangelho de Jesus Cristo segundo Lucas (Lc) e do livro dos Atos dos Apóstolos (At) forma a obra lucana. Seus destinatários primeiros, da segunda metade do século I $\mathrm{AD}$, são gentios helenistas que aderiram ao anúncio de que a esperança do antigo Israel se realiza no Messias Jesus de Nazaré, o querigma cristão. Essa expressão religiosa (o cristianismo primitivo) está inserida numa tradição já existente, o judaísmo. Ela precisa ser continuidade, autocompreender-se e fundamentar-se nas raízes dessa tradição, sob o risco de provocar uma ruptura definitiva que implicaria uma expressão avulsa e sem sustentação, tanto para os judeus quanto para os gentios que optassem pelo cristianismo. Esta pesquisa busca apresentar o texto final da obra lucana, a perícope de At 28,16-28, como sumário, clímax e paradigma da confirmação dessa continuidade e completude das esperanças de Israel no querigma cristão. O personagem Paulo, judeu helenista, apóstolo dos gentios, passa a ser o protagonista desse processo e, por isso, o livro dos Atos dos Apóstolos não só propõe sua inocência quanto às acusações dos líderes judaicos, como também o apresenta como imitador de seu mestre, Jesus, e modelo para os demais cristãos, especialmente quanto à sua fundamentação na tradição judaica, quanto à liberdade na prática dos costumes e leis mosaicas e quanto à abertura vocacional ao anúncio a todas as nações. Para tanto, a pesquisa acessa 0 texto grego, analisa-o em várias instâncias, além de traduzi-lo para o português, e apresenta um estudo exegético-teológico da perícope.

Palavras-chave: Obra lucana; Atos dos Apóstolos; Querigma cristão; Grego koiné. 


\section{0 mandamento do sábado no Decálogo: um estudo exegético de Ex 20,8-11; Dt 5,12-15}

Paulo Antônio Alves

Titulação: Mestre em Teologia

Orientador: Dr. Matthias Grenzer

Data da defesa: 25/03/2015

Resumo: O conteúdo desta dissertação é uma leitura do mandamento do sábado nas duas versões do Decálogo, Ex 20,8-11 e Dt 5,12-15. Essa leitura aponta algumas características fornecidas pelo próprio texto bíblico, enquanto estrutura do mandamento do Sábado e oferece também algumas contribuições da Tradição Rabínica e de Teólogos Cristãos sobre esse tema central, profundo e vasto. Ex 20,8-11 é uma formulação positiva, uma lei apodítica, uma lei/ ensinamento. Não impõe práticas culturais, e sim descanso, o qual deve ser consagrado a Deus. Como em Gn 2,1-4a, o descanso do sétimo dia é explicado como um limite colocado por Deus com seu poder criativo. Como o Templo delimitava um espaço, do mesmo modo o sábado delimita um tempo e o consagra a Deus. A motivação é estritamente teológica: faz memória da criação e do descanso divino do sétimo dia: uma libertação do nada, a qual encontra no seu término um tempo santo/consagrado porque separado e, abençoado porque fecundo, cheio de vida. Essas motivações são diferentes, mas ambas participam do mesmo projeto: dar a Israel, por meio do mandamento/lei/ensinamento do Sábado, um lugar de identidade vivido em um tempo separado: o sétimo dia. Dt 5,1215 tem como justificativa uma motivação de cunho antropológico, social e igualitário, que se estende inclusive à natureza, aos animais e à terra: faz memória da libertação da terra do Egito pela ação de Deus. Além desses dois importantes conceitos teológicos, Criação e Libertação, o mandamento do sábado veicula os conceitos de santidade, terra, povo eleito e do verbo guardar, lembrar, que é 
fazer memória atualizadora. O mandamento do sábado é atualizado por ambas as escolas para redefinir e fundamentar a identidade de Israel à luz do evento central para sua história: a libertação da terra do Egito. Além de fundamentar a identidade, o mandamento do sábado se constitui como fonte de alimento espiritual para Israel e para a Igreja, via teologia do cumprimento e não da ruptura ou substituição. Ele foi estruturado como centro do Decálogo, em suas duas versões, também ele possuindo um centro, outorgando-lhe um status de chave hermenêutica da Torah, coração da Aliança e das leis subsequentes.

Palavras-chave: Sábado; Criação; Libertação; Memória. 


\section{Moisés como imigrante em Madiã: estudo literário e histórico-teológico de Êxodo 2,15c-22d}

Marivan Soares Ramos

Titulação: Mestre em Teologia

Orientador: Dr. Matthias Grenzer

Data da defesa: 25/03/2015

Resumo: A presente pesquisa, fruto de um estudo literário e histórico-teológico de um texto do livro do Êxodo 2,15c-22d, tem como objetivo concentrar-se, de um modo especial, nas características que são atribuídas ao personagem que assume o protagonismo da história. A narrativa de Ex 2,15c-22d traz, ao ouvinte-leitor, cenas e personagens envolvidos numa trama surpreendente. Consoante a isso, emerge com grande protagonismo o personagem de Moisés, o qual, ao longo da narrativa, inquieta e questiona o ouvinte-leitor com seu comportamento. Desse modo, a narrativa apresenta alguns modelos morais que podem ser assimilados ou não pelo ouvinte-leitor. Além disso, a pesquisa se debruça sobre outros elementos que compõem a narrativa, a saber: os geográficos e os histórico-arqueológicos, sobretudo no que se refere à localização de Madiã, lugar onde se desenvolverá toda a narrativa aqui estudada. Deseja-se com isso que o ouvinte-leitor busque uma melhor percepção do contexto em que se passa a narrativa. Além disso, são estudados os detalhes da trama e a maneira como a voz do narrador se entrelaça com os discursos diretos e intensos dos personagens que, com Moisés, assumem destaque nas diversas partes da narrativa. Por fim, espera-se descobrir, nas entrelinhas do texto narrado, a reflexão teológica que emerge dele.

Palavras-chave: Bíblia; Moisés; Imigrante; Madiã. 